\title{
The geographic scale of genetic differentiation in the feral pigeon (Columba livia): implications for management
}

\author{
Gwenaël Jacob · Anne-Caroline Prévot-Julliard • \\ Emmanuelle Baudry
}

\begin{abstract}
Understanding the genetic connectivity among populations of spreading and problematic species is important to determine the spatial scale at which management actions need to be conducted. The feral pigeon (Columba livia) is considered to be a pest or an invasive species in many cities around the world, leading to frequent attempts to control its populations. In the present study, we used microsatellites markers to investigate the relationship between genetic structure and geographic distance among feral pigeons from different locations, and the patterns of genetic differentiation at two geographic scales, within and between urbanised areas. A Mantel's test revealed that
\end{abstract}

G. Jacob · A.-C. Prévot-Julliard · E. Baudry $(\bowtie)$ Laboratoire Ecologie, Systématique et Evolution, UMR 8079, Université Paris-Sud-CNRS-AgroParisTech, Université Paris-Sud, Orsay, France

e-mail: emmanuelle.baudry@u-psud.fr

G. Jacob

e-mail: gwenael.jacob@unifr.ch

G. Jacob

Department of Biology, Unit of Ecology \& Evolution, University of Fribourg, Chemin du Musée 10,

1700 Fribourg, Switzerland

A.-C. Prévot-Julliard

Centre des Sciences de la Conservation (CESCO), UMR7204, CNRS-MNHN-UPMC, Muséum National d'Histoire Naturelle, CP 51, 55 rue Buffon, Paris 5, France the levels of genetic differentiation increased significantly with the geographic distance separating the locations. We also found that neighbouring locations within urban areas are usually not genetically differentiated, suggesting that all of the feral pigeons in an urban zone constitute a single management unit. Our results suggest that in large, interconnected cities control by culling at the scale of a neighbourhood, in addition of generating ethical issues, will not be effective to decrease pigeon population sizes.

Keywords Genetic structure Problem species . Management · Dispersal · Isolation-by-distance . Feral pigeon $\cdot$ Columba livia

\section{Introduction}

Understanding the connectivity among populations of spreading and problematic species is important to determine the spatial scale at which management actions need to be conducted. If a local population of an invasive species targeted for control is not connected by dispersal to other populations, then it can be considered a management unit, i.e. a demographically independent populations whose population dynamics depends on local birth and death rates rather than on immigration (Palsbøll et al. 2007), and it can be managed independently (Robertson and Gemmell 2004). Otherwise, if the local population is part of a network of local populations connected by dispersal, 
thus constituting a metapopulation, management programs should be conducted at the scale of the global metapopulation to be efficient (Robertson and Gemmell 2004). Molecular genetics has provided a valuable means of determining connectivity between populations: negligible genetic differentiation between populations is indicative of significant gene flow, whereas significant differentiation between populations indicates limited dispersal (Rollins et al. 2006).

In the present study, we used microsatellite markers to investigate the genetic relationship between feral pigeons (Columba livia) within and between urbanised areas. Feral Pigeons are free-living descendents of domestic pigeons (Johnston and Janiga 1995). Well adapted to the urban environment, they live in almost every large city around the world (Jerolmack 2008). Within these urban areas, the high availability of food and of nesting sites, the low predation pressure and the buffered climatic conditions often allow their populations to reach high densities (Johnston and Janiga 1995). Large numbers of pigeons are often branded as causing problems in the cities, like damage to buildings and transmission of disease and parasites (e.g. Jerolmack 2008). Therefore, in many cities feral pigeon is considered to be a pest or an invasive species, leading to frequent attempts to control its populations. A number of control methods are used with variable efficiency, which can be divided in three main categories: increase of mortality, usually by culling but also by the promotion of predators, reduction of reproductive success by removing the eggs or by using sterilization or contraceptive methods, or reduction of habitat carrying capacity by decreasing the availability of nesting sites and food (reviewed in Haag-Wackernagel 2002 and in Giunchi et al. 2012). In large cities, for practical reasons, control programs are usually implemented at the scale of a neighbourhood. In such cases, the efficiency of the programs will depend, among other factors, on the connectivity between the groups of pigeons inhabiting the different neighbourhoods within the city (Robertson and Gemmell 2004). Ours represent the first attempt to characterize the genetic structure of feral pigeon populations. This information will be useful to determine the connectivity between groups of pigeons at the geographic scale at which actions to decrease population sizes are most likely to succeed.

\section{Materials and methods}

Sample collection

We analysed DNA of feral pigeons originating from fourteen locations in eight geographically distinct urbanised areas in France, Spain and Switzerland. We conducted more intensive sampling in a contiguous and densely urbanised area that included the city of Paris and its suburbs, referred to as Île-de-France (IdF), where six different locations were sampled. The study areas also included a sparsely but continuously urbanised area situated along the Rhone valley in France, which we refer to as the Montélimar/Viviers area (MV), where we sampled three different locations. In total, we collected 529 blood or feather samples from fourteen locations (Table 1). In IdF, we used blood samples collected from pigeons captured either in a dovecote (Fontenay and Pantin) or at a feeding point. In the eight other locations, we collected recently moulted feathers in the vicinity of roosting sites. Only 2 or 3 feathers were collected at each roosting site to limit repeated sampling of the same individuals (but see below how we have ensured that samples were from different individuals).

\section{Genetic methods}

Feathers were kept at room temperature in paper envelops until DNA extraction. We isolated DNA from feather samples by incubating $1-2 \mathrm{~cm}$ of the shaft cut into pieces in $1.8 \mathrm{~mL}$ ASL buffer (Qiagen) $+20 \mu \mathrm{L}$ proteinase $\mathrm{K}$. Blood was stored in buffer PBS + EDTA $(3 \% \mathrm{v} / \mathrm{v})$ and was kept frozen at $-20{ }^{\circ} \mathrm{C}$ until DNA extraction. We extracted DNA using a Tissue Kit (Qiagen) and followed the manufacturer's protocol for DNA extraction from blood or feather samples. DNA was eluted in $2 \times 100 \mu \mathrm{l} \mathrm{AE}$ buffer (Qiagen) and stored at $-20{ }^{\circ} \mathrm{C}$. We amplified seven microsatellite loci (Cli $\mu$ 17, Cli $\mu \mathrm{T} 17$, Cli $\mu$ D16, Cli $\mu$ D2, Cli $\mu$ D01, Cli $\mu$ T13 and Cli DD19) developed for domestic breeds of the rock pigeon (Traxler et al. 2000). F-primers were fluorescently labelled using commercially available dyes, FAM, VIC, NED and PET. PCRs were setup in $10 \mu \mathrm{l}$ volume containing $1 \times$ Multiplex Master Mix (Qiagen) and $0.2 \mu \mathrm{M}$ each primer. We amplified the seven microsatellite loci in a single PCR reaction. PCR conditions were as follow: $15 \mathrm{~min}$ at $94{ }^{\circ} \mathrm{C}$ for DNA 
Table 1 Principal characteristics of the 14 locations analysed in the present study

\begin{tabular}{lllllllll}
\hline Populations & Abb. & Samples & Latitude & Longitude & $n$ & $H_{\mathrm{O}}$ & $F_{\text {IS }}$ & $r$ \\
\hline Bangor & $\mathrm{Bng}$ & $\mathrm{f}$ & $47^{\circ} 18.55 \mathrm{~N}$ & $3^{\circ} 11.23 \mathrm{~W}$ & $46(64)$ & 0.70 & 0.04 & 5.92 \\
Dijon & $\mathrm{Djn}$ & $\mathrm{f}$ & $47^{\circ} 19.26 \mathrm{~N}$ & $5^{\circ} 1.57 \mathrm{E}$ & $27(33)$ & 0.62 & 0.17 & 8.62 \\
Zurich & $\mathrm{Zh}$ & $\mathrm{f}$ & $47^{\circ} 22.30 \mathrm{~N}$ & $8^{\circ} 32.40 \mathrm{E}$ & $31(36)$ & 0.75 & 0.05 & 7.52 \\
Carcassonne & $\mathrm{Crc}$ & $\mathrm{f}$ & $43^{\circ} 12.21 \mathrm{~N}$ & $2^{\circ} 21.48 \mathrm{E}$ & $27(31)$ & 0.78 & 0.09 & 9.87 \\
Barcelone & $\mathrm{Brc}$ & $\mathrm{f}$ & $41^{\circ} 24.14 \mathrm{~N}$ & $2^{\circ} 11.17 \mathrm{E}$ & $17(19)$ & 0.78 & 0.06 & 7.83 \\
Montélimar/Viviers $(M V)$ & & & & & & \\
Montélimar-SNCF & $\mathrm{MtS}$ & $\mathrm{f}$ & $44^{\circ} 33.32 \mathrm{~N}$ & $4^{\circ} 44.42 \mathrm{E}$ & $27(39)$ & 0.79 & 0.02 & 7.54 \\
Montélimar-ZAC & $\mathrm{MtZ}$ & $\mathrm{f}$ & $44^{\circ} 32.20 \mathrm{~N}$ & $4^{\circ} 44.20 \mathrm{E}$ & $42(47)$ & 0.81 & 0.01 & 7.91 \\
Viviers & $\mathrm{Vvr}$ & $\mathrm{f}$ & $44^{\circ} 28.54 \mathrm{~N}$ & $4^{\circ} 41.28 \mathrm{E}$ & $28(36)$ & 0.81 & 0.03 & 8.50 \\
Ile-de-France (IdF) & & & & & & & \\
Fontenay & Fnt & $\mathrm{b}$ & $48^{\circ} 51.00 \mathrm{~N}$ & $2^{\circ} 28.90 \mathrm{E}$ & $117(117)$ & 0.80 & 0.01 & 8.18 \\
Pantin & $\mathrm{Pnt}$ & $\mathrm{b}$ & $48^{\circ} 53.37 \mathrm{~N}$ & $2^{\circ} 24.46 \mathrm{E}$ & $27(27)$ & 0.75 & 0.06 & 7.69 \\
St Denis & $\mathrm{StD}$ & $\mathrm{b}$ & $48^{\circ} 52.11 \mathrm{~N}$ & $2^{\circ} 21.90 \mathrm{E}$ & $19(19)$ & 0.79 & 0.04 & 8.13 \\
Satragne & $\mathrm{Stg}$ & $\mathrm{b}$ & $48^{\circ} 52.32 \mathrm{~N}$ & $2^{\circ} 21.19 \mathrm{E}$ & $21(21)$ & 0.817 & 0.03 & 8.49 \\
Vanves & $\mathrm{Vnv}$ & $\mathrm{b}$ & $48^{\circ} 49.40 \mathrm{~N}$ & $2^{\circ} 18.21 \mathrm{E}$ & $21(21)$ & 0.873 & -0.07 & 8.49 \\
Orly & Orl & $\mathrm{b}$ & $48^{\circ} 43.38 \mathrm{~N}$ & $2^{\circ} 24.70 \mathrm{E}$ & $19(19)$ & 0.815 & 0.00 & 8.87 \\
Total & & & & $469(529)$ & 0.778 & 0.04 & 8.11 \\
\hline
\end{tabular}

We report the name used to identify the locations and its abbreviation, the type of sample analyzed ( $b$ blood, $f$ feather), their geographic coordinates, the number of unique genotypes per locations ( $n$, the number of samples is indicated in brackets), the level of observed heterozygosity $\left(H_{\mathrm{O}}\right)$, the coefficient of inbreeding $\left(F_{\mathrm{IS}}\right)$ and the allelic richness $(r)$, corrected for variation in sample size using the rarefaction method described by Petit et al. (1998)

denaturation, 35 cycles of $\left[30 \mathrm{~s}\right.$ denaturation at $94{ }^{\circ} \mathrm{C}$, 3 min hybridisation at $54{ }^{\circ} \mathrm{C}$ and $30 \mathrm{~s}$ elongation at $72{ }^{\circ} \mathrm{C}$ ] and a final elongation step of $15 \mathrm{~min}$ at $72{ }^{\circ} \mathrm{C}$. The PCR products were mixed with an internal size standard (Genescan 500LIZ, Applied Biosystems) and analysed using an ABI 3700 semi-automated DNA sequencer (Applied Biosystems). Negative controls were used to check for cross-contaminations between tubes during DNA extraction and amplification. We calculated the size of the microsatellite alleles using GENESCAN 4.0 (Applied Biosystems).

\section{Genetic analyses}

Because repeated genotypes may indicate repeated sampling of the same individual, within locations, we searched for multiple occurrences of the same multilocus genotypes using GenalEx 6 (Peakall and Smouse 2006).

We tested for a significant deviation from HardyWeinberg Equilibrium (HWE) for each locus at each location using the algorithm of Guo and Thompson (1992) as implemented in ARLEQUIN 3.11 (Excoffier et al. 2005). For each location, we calculated the average level of observed heterozygosity, $H_{\mathrm{O}}$, the coefficient of inbreeding, $F_{\text {IS }}$, and the allelic richness, $r$, using FSTAT 2.93 (Goudet 2001). Measures of allelic richness were corrected for variation in sample size using the rarefaction method described by Petit et al. (1998).

We estimated the genetic differentiation among locations using both $F_{S T}$ (based on the infinite allele model of mutation) and $R_{S T}$ (based on the stepwise model of mutation) statistics, calculated with ARLEQUIN 3.11. The procedure proposed by Hardy et al. (2003) and implemented in SPAGEDI (Hardy and Vekemans 2002) suggested that $R_{S T}$ was a better estimator than $F_{S T}$ for describing the genetic differentiation among our feral pigeon locations ( $p$ $R_{S T}>F_{S T}, p$ value $\left.=0.01\right)$. We therefore only present $R_{S T}$ values, calculated with ARLEQUIN 3.11. A permutation procedure $(10,000$ steps $)$ was used to assess the significance of the estimated $R_{S T}$ values.

We tested whether Slatkin's isolation-by-distance model (Slatkin 1993) of increased genetic distance with increased geographic distance is appropriate among locations of feral pigeons. The significance of the Pearson correlation coefficient between genetic 
differentiation and geographic distance was assessed with a Mantel test (1,000 permutations) using GenalEx 6 (Peakall and Smouse 2006).

\section{Results and discussion}

\section{Genetic results}

The genotyping success per locus ranged from 98.5 to $100.0 \%$. The low values of the probability of identity (from $5.3 \times 10^{-3}$ in Bgr to $1.5 \times 10^{-3}$ in Vvr) suggests that each multi-locus genotype identifies a unique individual. In locations where feathers were sampled, we observed multiple occurrences of some genotypes, which indicates that some individuals were sampled more than once. We therefore kept only one of the duplicate genotypes, excluding a total of 60 samples (Table 1). All other genotypes within locations differed by at least three alleles. The total number of alleles per microsatellite locus ranged from 9 to 26. When examining each locus per population and correcting for multiple tests, only one locus was significantly deviated from Hardy-Weinberg expectations. Cli $\mu$ D19 showed a significant heterozygote deficiency in all locations, suggesting the presence of a frequent nonamplifying allele (the frequency estimates for this potential null alleles is 0.60). Cli $\mu$ D19 was therefore excluded from further analyses. Whereas one location, Vnv, was characterised by a level of observed heterozygosity $\left(H_{\mathrm{o}}=0.873\right)$ slightly higher than expected under HWE (not significantly so), the levels of $H_{\mathrm{o}}$ were lower than expected in all the other populations, resulting in positive values of the inbreeding coefficient. This result suggests that some level of population genetic substructuring and/or inbreeding may occur, although these processes are not strong enough to induce a marked deviation from HWE. The lowest level of allelic richness was found in the Bng location (5.92 allele/locus, Table 1), while the remaining 13 locations showed levels of allelic richness ranging from $7.52(\mathrm{Zh})$ to 9.75 (Crc). Bng is situated in Belle-Île, an island separated from the closest continental group of pigeons by a distance of $20 \mathrm{~km}$. The overall small population size and geographic isolation may partly explain the low level of genetic diversity observed.

We observed a high level of genetic differentiation between geographically distant locations (Table 2). Estimated pairwise $R_{S T}$ were almost always significant between locations situated in different urbanised areas. The estimated levels of genetic differentiation increased significantly with the geographic distance separating the locations (Fig. 1, Mantel test, $p$ value $=0.001)$. This result suggests that effective dispersal between urbanised areas is rare and decreases rapidly with the geographic distance. This is consistent with the results of the study from Hetmanski (2007), where no emigration to other towns in the neighbourhood of the study area were observed. Our findings confirm that dispersal events between cities are a rare event, indicating strong philopatry in the species.

We found that the geographical scale at which the analysis was conducted largely influenced the pattern of genetic differentiation between samples. Indeed, between the six locations within the IdF region and between the 3 locations within the MV region, we observed very low levels of genetic differentiation $\left(R_{S T}=0.00-0.06\right)$ and most pairwise $R_{S T}$ estimates were not significantly different from zero (Table 2 ).

This very low level of genetic differentiation between groups of pigeons within the same large city may be observed even if they are not connected by dispersal if the groups originated recently from the same founding population, for example through escaped racing homers (Stringham et al. 2012). However, this does not seem very likely because the presence of feral pigeons is attested in France since the end of the nineteenth century, with an important increase of urban populations within Paris at the beginning of the twentieth century (Skandrani et al. 2014 and references therein). Given the short generation time of feral pigeons (they become sexually mature when 6 months old, Johnston and Janiga 1995), in the absence of gene flow, the number of generations would have been sufficient for groups of pigeons within Paris to accumulate genetic differentiation by genetic drift. We therefore argue that groups of pigeons within the same large urbanized area do not show genetic differentiation because they are connected by dispersal. This is in agreement with the results of Morand-Ferron et al. (2009), who found that the pigeons inhabiting the downtown area of Montréal seem to behave as a single population that distributes among foraging sites spread over the city centre in proportion to the quantity of food offered. Furthermore, Hetmanski (2007) studied dispersion in five feral pigeon colonies within the city centre of Słupsk, Poland, and showed that, whereas hardly any adult 
Table 2 Pairwise genetic differentiation between locations measured as $R_{S T}$ (below the diagonal)

\begin{tabular}{|c|c|c|c|c|c|c|c|c|c|c|c|c|c|c|}
\hline & Bng & Fnt & Pnt & $\mathrm{StD}$ & Stg & Vnv & Orl & Djn & $\mathrm{Zh}$ & $\mathrm{MtS}$ & $\mathrm{MtZ}$ & Vvr & $\mathrm{Crc}$ & Brc \\
\hline Bng & - & $* *$ & $* *$ & n.s. & $* *$ & $*$ & $*$ & $* *$ & $* *$ & $* *$ & $* *$ & $* *$ & $* *$ & $* *$ \\
\hline Fnt & 0.10 & & * & $* *$ & n.s. & * & n.s. & n.s. & $* *$ & $* *$ & $* *$ & $* *$ & $* *$ & $* *$ \\
\hline Pnt & 0.06 & 0.02 & - & n.s. & n.s. & n.s. & n.s. & $* *$ & $* *$ & $* *$ & $* *$ & $* *$ & $* *$ & $* *$ \\
\hline StD & 0.03 & 0.05 & 0.00 & - & n.s. & n.s. & n.s. & $* *$ & $* *$ & $* *$ & $* *$ & $* *$ & $* *$ & $* *$ \\
\hline Stg & 0.14 & 0.00 & 0.02 & 0.06 & - & $* *$ & n.s. & n.s. & $* *$ & $* *$ & $* *$ & $* *$ & $* *$ & $* *$ \\
\hline Vnv & 0.04 & 0.03 & 0.00 & 0.00 & 0.05 & - & n.s. & $* *$ & $* *$ & $* *$ & $* *$ & $* *$ & $* *$ & $* *$ \\
\hline Orl & 0.05 & 0.01 & 0.00 & 0.01 & 0.02 & 0.00 & - & * & $* *$ & $* *$ & $* *$ & $* *$ & $* *$ & $* *$ \\
\hline Djn & 0.18 & 0.02 & 0.06 & 0.09 & 0.00 & 0.09 & 0.06 & - & $* *$ & $* *$ & $* *$ & $* *$ & $* *$ & $* *$ \\
\hline $\mathrm{Zh}$ & 0.32 & 0.15 & 0.25 & 0.26 & 0.14 & 0.26 & 0.20 & 0.16 & - & $*$ & $*$ & n.s. & n.s. & $* *$ \\
\hline $\mathrm{MtS}$ & 0.30 & 0.17 & 0.28 & 0.28 & 0.18 & 0.28 & 0.21 & 0.19 & 0.04 & - & n.s. & $*$ & n.s. & $* *$ \\
\hline $\mathrm{MtZ}$ & 0.33 & 0.17 & 0.27 & 0.29 & 0.16 & 0.28 & 0.22 & 0.17 & 0.02 & 0.01 & - & n.s. & $*$ & $* *$ \\
\hline Vvr & 0.26 & 0.07 & 0.19 & 0.21 & 0.07 & 0.20 & 0.13 & 0.09 & 0.02 & 0.04 & 0.02 & - & n.s. & $* *$ \\
\hline $\mathrm{Crc}$ & 0.26 & 0.10 & 0.21 & 0.22 & 0.11 & 0.22 & 0.15 & 0.11 & 0.01 & 0.04 & 0.03 & 0.01 & - & $* *$ \\
\hline $\mathrm{Brc}$ & 0.32 & 0.21 & 0.32 & 0.30 & 0.26 & 0.32 & 0.22 & 0.24 & 0.11 & 0.18 & 0.20 & 0.17 & 0.09 & - \\
\hline
\end{tabular}

The significance of the $p$ values was assessed from 99 permutations and is reported above the diagonal, as $* *(p$ value $<0.01)$, $*(p$ value $<0.05)$ and n.s. $(p$ value $>0.05)$. The locations within Île-de-France and Montélimar/Viviers regions are indicated by italics

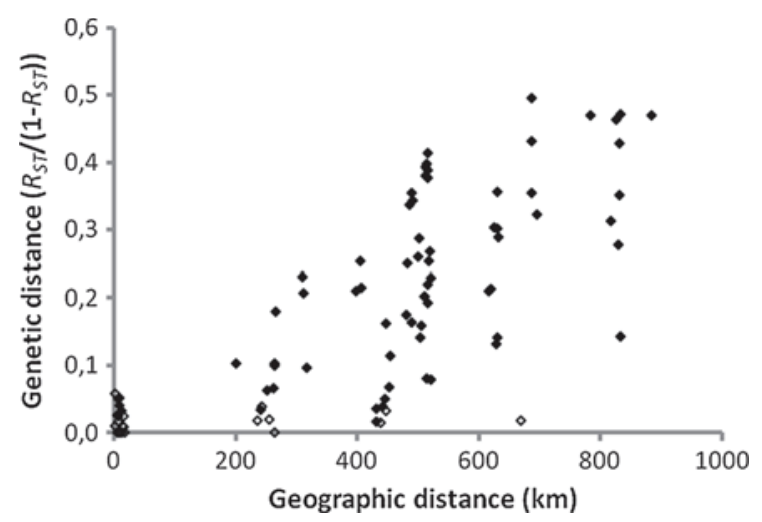

Fig. 1 Graphical illustration of the level of pairwise genetic differentiation (measured as $R_{S T}$ ) increasing with the geographic distance between locations (measured as the Euclidean distance between the locations). $R_{S T}$ values that were significantly different from zero at the 0.05 level are indicated with a filled symbol; non-significant values with an open symbol

birds left their breeding colonies, dispersion among young birds between colonies within the city was relatively high and remained at a stable level of 20-33\% per year. Even in cases where pigeons exhibit high site-fidelity, like in Barcelona, exchanges of pigeons between adjacent populations also occur occasionally (Sol and Senar 1995). Our results therefore confirm with a genetic approach previous suggestions that pigeons within an urbanized area constitute a single management unit, as proposed by Giunchi et al. (2012).

Implication for management

As mentioned above, three main classes of methods are used to control pigeon populations: culling and decrease of reproductive success, which aims at directly decreasing the number of birds, and reduction of habitat carrying capacity (Giunchi et al. 2012). Because all the pigeons that inhabit the same urbanized area constitute a single large population, in any given area within a large city, the local density of pigeons will depend on the level of resource available locally but also on the number of birds present in the whole city (Morand-Ferron et al. 2009). This implies that, in a large city, control programs based on culling and decrease of reproductive success should be conducted throughout the urban area, which will usually be very difficult for practical reasons. Furthermore, culling has been shown to be a generally ineffective control method in pigeons (Giunchi et al. 2012). Because they have a high intrinsic rate of increase as well as strong density-dependence for several key demographic parameters (reproductive success and recruitment rate increase at lower population densities whereas mortality decreases e.g. Haag 1991; Johnston and Janiga 1995; Hetmanski 2007; 
Hetmanski and Barkowska 2007), populations of feral pigeons have a high compensatory potential. Furthermore, when individuals are removed from a location, intraspecific competition decreases locally, which makes the location more attractive for individuals from adjacent localities (Sol et al. 2000). Therefore, even when large numbers of birds are killed, there is no substantial lasting effect on the size of the population (e.g. Sol and Senar 1995; Kautz and Malecki 1990; Sol and Senar 1992). In addition, killing large numbers of pigeons is ethically problematic and may be difficult to accept for the general public. In opposite, the reduction of habitat carrying capacity by the reduction of food availability and nesting sites is currently regarded as the best way to control pigeon populations, because it can produce a long-lasting reduction in population size (Haag-Wackernagel 1993) and also because it is usually well accepted by the general public (Giunchi et al. 2012).

Many cities throughout the world conduct public policies to control pigeons. We provide here results on the ecology of feral pigeon that could help local authorities to be more efficient. Indeed, we recommend that in large urban areas, management policies focus on decreasing the availability of food and nesting locations, which would allow for local control of the population size while preventing immigration from neighbouring locations within the same urban area. If culling or of reproductive success decrease programs are preferred, they should then be conducted throughout the urban area.

Acknowledgments The authors would like to thank Daniel Simberloff and two anonymous reviewers for their valuable comments on a previous version of this paper. This study is part of a larger research program on urban pigeons supported by grants from the ANRJC (ANR-05-JCJC-0098-01), the Region Ile-de-France (no. 06-1064 MN 07) and the Seine-Saint-Denis department.

\section{References}

Excoffier L, Laval G, Schneider S (2005) Arlequin 3.0: an integrated software package for population genetics data analysis. Evol Bioinform Online 1:47-50

Giunchi D, Albores-Barajas Y, Baldaccini N, Vanni L, Soldatini C (2012) Feral pigeons: problems, dynamics and control methods. In: Soloneski S (ed) Integrated pest management and pest control-current and future tactics. InTech, pp 215-240. doi: $10.5772 / 31536$

Goudet J (2001) FSTAT, a program to estimate and test gene diversities and fixation indices. Institute of Ecology and
Evolution, University of Lausanne, Lausanne, Switzerland. http://www2.unil.ch/popgen/softwares/fstat.htm

Guo SW, Thompson EA (1992) Performing the exact test of Hardy-Weinberg proportion for multiple alleles. Biometrics 48:361-372

Haag D (1991) Population density as a regulator of mortality among eggs and nestlings of feral pigeons (Columba livia domestica) in Basel, Switzerland. In: Pinowski J, Kavanagh BP, Górski W (eds) Nestling mortality of granivorous birds due to microorganisms and toxic substances. Polish Scientific Publishers, Warsaw, pp 21-31

Haag-Wackernagel D (1993) Street pigeons in basel. Nature 361:200

Haag-Wackernagel D (2002) Feral pigeons: management experiences in Europe. In: Atti $2^{\circ}$ Convegno Nazionale sulla Fauna Urbana "Specie ornitiche problematiche: biologia e gestiona nelle città e nel territorio", pp 25-37, Firenze, 10 giugno 2000, ARSIA e LIPU. Regiona Toscana, Firenze

Hardy OJ, Vekemans X (2002) SPAGEDi: a versatile computer program to analyse spatial genetic structure at the individual or population levels. Mol Ecol Notes 2:618-620

Hardy OJ, Charbonnel N, Freville H, Heuertz M (2003) Microsatellite allele sizes: a simple test to assess their significance on genetic differentiation. Genetics 163:1467-1482

Hetmanski T (2007) Dispersion asymmetry within a feral pigeon Columba livia population. Acta Ornithol 42:23-31

Hetmanski T, Barkowska M (2007) Density and age of breeding pairs influence feral pigeon, Columba livia, reproduction. Folia Zool 56:71-83

Jerolmack C (2008) How pigeons became rats: the culturalspatial logic of problem animals. Soc Probl 55:72-94

Johnston RF, Janiga M (1995) Feral pigeon. Oxford University Press, New York

Kautz JE, Malecki RA (1990) Effects of harvest on feral rock dove survival, nest success and population size. Fish and wildlife technical report (USA). No. 31

Morand-Ferron J, Lalande E, Giraldeau LA (2009) Large-scale input matching by urban feral pigeons (Columba livia). Ethology 115:707-712

Palsbøll PJ, Berube M, Allendorf FW (2007) Identification of management units using population genetic data. Trends Ecol Evol 22:11-16

Peakall R, Smouse PE (2006) GenAlEx 6: genetic Analysis in Excel. Population genetic software for teaching and research. Mol Ecol Notes 6:288-295

Petit RJ, El Mousadik A, Pons O (1998) Identifying populations for conservation on the basis of genetic markers. Conserv Biol 12:844-855

Robertson BC, Gemmell NJ (2004) Defining eradication units to control invasive pests. J Appl Ecol 41:1042-1048

Rollins LA, Woolnough AP, Sherwin WB (2006) Population genetic tools for pest management: a review. Wildl Res 33:251-261

Skandrani Z, Lepetz S, Prévot-Julliard A-C (2014) Nuisance species: beyond the ecological perspective. Ecological Process 3:3

Slatkin M (1993) Isolation by distance in equilibrium and nonequilibrium populations. Evolution 47:264-279

Sol D, Senar JC (1992) Comparison between two censuses of Feral Pigeon Columba livia var. from Barcelona: an 
evaluation of seven years of control by killing. Butlleti del Grup Catala d'Anellament 9:29-32

Sol D, Senar JC (1995) Urban pigeon population: stability, home range, and the effect of removing individuals. Can J Zool 73:1154-1160

Sol D, Santos DM, Cuadrado M (2000) Age-related feeding site selection in urban pigeons (Columba livia): experimental evidence of the competition hypothesis. Can J Zool 78:144-149
Stringham SA, Mulroy EE, Xing J, Record D, Guernsey MW, Aldenhoven JT, Osborne EJ, Shapiro MD (2012) Divergence, convergence, and the ancestry of feral populations in the domestic rock pigeon. Curr Biol 22:302-308

Traxler B, Brem G, Muller M, Achmann R (2000) Polymorphic DNA microsatellites in the domestic pigeon Columba livia var. domestica. Mol Ecol 9:366-368 